\title{
Potassium cyanide and the effect on the rate of decomposition of mice in grave-soil
}

\begin{abstract}
As a body decomposes, a multitude of physiochemical changes occur that are interdependent on physical factors including temperature, humidity and $\mathrm{pH}$, and victim characteristics such as weight, clothing and ante-mortem pathology. One aspect that has not been investigated is to what extent poisons such as cyanides have on a decomposing cadaver. Cyanides are used extensively throughout industry from mining to electroplating, and found in some fruits. They have also been used to commit murders and suicides. Therefore, it is necessary to determine whether cyanide has any effect on the rate of decomposition of a body buried in a soil environment as well as to assess whether overall mass loss is a viable post-mortem interval estimation method. One hundred dead house mice (Mus. musculus) were weighed and then intragastrically injected with doses of $0,5000,10000,20000$ and 30000 parts per million (ppm) potassium cyanide solution. The mice were then buried in separate containers of $300 \mathrm{~g}$ top soil. Five M. musculus samples were randomly assigned to one of four Day Removal Categories (DRCs). The removal categories were 7, 14, 21 and 30 days after initial burial. In each DRC, the mice were removed, cleaned, photographed, characterised using a scoring system developed by Megyesi et al., ${ }^{1}$ and then weighed again. A percentage change was calculated between the initial and removal masses. Statistical analysis was conducted using Levene Test, oneway ANOVA and Welch F-Test. Results suggested that potassium cyanide concentration was not statistically significant to the overall rate of decomposition observed, however photographs and decompositional scoring suggested there was a localised effect observed by an increased concavity of the stomach and abdominal areas. Critical analysis deemed mass loss an unviable post-mortem interval estimation tool due to a dependence on numerous factors, many of which are lost at the time of death.
\end{abstract}

Keywords: concentration, decomposition, mass change, poisoning, potassium cyanide, mus musculus, grave-soil
Volume I Issue 2 - 2015

Thomas Neil MacDonald

SciTech Department, Bournemouth University, United Kingdom

Correspondence: Thomas Neil MacDonald, SciTech Department, Bournemouth University, Talbot Campus, Poole, Dorset, BHI 2 5BB, Tel +4479490573I5,

Email thomasnmacdonald@gmail.com

Received: August 09, 2015 | Published: October 13, 2015
Abbreviations LD50, Median lethal dose for $50 \%$ of a population; DRC, Day Removal Category; KCN, Potassium Cyanide; MIN, Mouse Identification Number; MRN, Mouse Reference Number; ppm, Parts per million; SMC, Soil Moisture Content; SPSS, Statistical Package for the Social Sciences Statistics Predictive; WHC, Water Holding Capacity; PMI, Post-Mortem Interval; DNA, Deoxyribonucleic Acid; RNA, Ribonucleic Acid; TBS, Total Body Score

\section{Introduction}

When an individual dies, a process of physiochemical change begins. These changes occur during the different stages of decomposition. ${ }^{2}$ Knowing the physiochemical changes that occur during decomposition can help pathologists establish a post-mortem interval (PMI). The PMI is the time between when a person has died and when they are discovered. Accurate estimations of PMIs are one of the cardinal objectives along with victim identification and cause of death. PMI determination can assist forensic scientists and detectives validate or reject alibis and as well as limit the number of likely suspects. Traditionally, early post-mortems used the soft tissue indicators: rigor mortis, algor mortis and hypostasis to estimate PMI. As the interval lengthens, morphological decomposition attributes, i.e. putrefaction, autolysis and bloating were used. A newly emerging entomological viewpoint has been used to estimate PMI. ${ }^{3}$ Unfortunately, all the forensic techniques used today usually give dubious and vague answers and, to a degree, remain unreliable and inaccurate. It is generally accepted that the longer the PMI, the less precise the estimation. For this reason, researches into factors influencing cadaver decomposition are indispensable for forensic scientists and environmental agencies. Many field studies using both human bodies ${ }^{4,5}$ and animal surrogates ${ }^{2,6-9}$ have been undertaken to assess decomposition processes in grave-soil under controlled conditions. Grave-soil is a complex system interdependent on chemical, biological and physical processes that both influence and are influenced by inclusion of a decomposing body. Physical texture characteristics like $\mathrm{pH}$, temperature ${ }^{10,11}$ and moisture ${ }^{12}$ have been investigated to understand how these affect decomposition of the cadaver. It was considered these parameters had little effect on decomposition ${ }^{13}$ until the 21 st century. ${ }^{10,14}$ However, knowledge of the influence poisons have on decomposition processes of edaphic parameters is highly limited ${ }^{15}$ and has not been investigated fully. Ergo, there is a need for both experimental and evidence-based data collection to be employed to identify patterns of change in biological constituents of grave-soils, in order to facilitate the standardisation of collection, recording and analysis methods in forensic science. Cyanide salts are widely available in industries involved with insecticides, metal polishing materials, jewelry cleaning, acrylonitrile manufacture, electroplating, and to a lesser extent, in photographic solutions, ${ }^{16}$ as well as being found naturally in Prunus species (apple seeds and cherry and apricot pits), smoke inhalation and sodium nitroprusside infusion. ${ }^{17-19}$ Cyanide salts are made up of two important elements; carbon and nitrogen. These elements are found in roughly 
almost all organic materials including deoxyribonucleic acid (DNA), ribonucleic acid (RNA), proteins, amino acids, food sources and cell membranes. The cadaver itself is approximately $20 \%$ carbon, so it is surprising that little is known on about the fate of carbon and nitrogen in grave-soil.

Decomposition is a natural system of breaking down and recycling nutrients from organic material by a complex organisation of thousands of different species of biological consumers. These consumers include bacteria and fungi amongst many others. Whilst most bacteria, fungi and other decomposers are susceptible to cyanides leading to phenotypic changes such as decreases in growth, mutations, altered respiration and death, there are some soil-borne bacteria (Pseudomonas pickettii, Klebsiella pneumonia and Alcaligenesxylosozidans $)^{20}$ and fungi (Fusariumsolanim) ${ }^{20}$ that have become adapted to being able to use cyanide salts as sources of carbon and nitrogen through cyanide detoxification mechanisms and the use of Rhodanese enzymes ${ }^{21,22}$ as well as cadaver carbon and nitrogen. Nevertheless, cyanide can poison microorganisms ${ }^{23}$ and may, therefore, retard decomposition. To date, there is little research on whether the rate of decomposition observed on a cadaver is affected if it has cyanide salts within it. The objectives of this research were to determine whether potassium cyanide concentrations have an empirical effect on the mass loss of a cadaver, to identify whether potassium cyanide results in qualitative change in localized areas of a cadaver and to establish whether total mass loss is a viable method for post-mortem interval estimation.

\section{Materials and methods}

Before the investigative experiment could be conducted; two preliminary tests were performed to establish key properties of the soil that was to be used. Firstly, the water holding capacity (WHC) tests, and secondly, the soil moisture content (SMC) test. Both these tests determined the soil's physical properties in regard to water that assisted in the reliability of soil standardisation and confidence in a decrease in soil variability. Before both preliminary tests were conducted, the Westland Horticulture Ltd topsoil was sifted for any stones.

\section{Animals and experimental methodology}

One hundred $500 \mathrm{ml}$ polypropylene containers with lids were filled with $300 \mathrm{~g}$ of Westland Horticulture Ltd topsoil at $60 \% \mathrm{WHC}$ established through preliminary tests. The soil filled roughly twothirds of the plastic container, leaving a one-third air pocket. In the middle of each lid, five air holes were created with a knife. The lids were labelled with the $\mathrm{KCN}$ concentration conditions in ppm, Mouse Reference Number (MRN), the mouse sample weight and a KCN toxicity warning. Each container contained one mouse sample. One hundred white mice (M. musculus) were bought from a commercial supplier (Reptiles Plus, Bournemouth, United Kingdom). All mice were killed humanely by the breeder for the pet food trade and were not killed for this experiment. The mice had been previously frozen and were slowly defrosted at ambient room temperature. The samples were weighed to three decimal places and issued an MRN. Experimental stock solutions of KCN (Acros Organic, Loughborough, United Kingdom) were produced at concentrations of 0ppm, 5000ppm, 10000ppm, 20000ppm and 30000ppm respectively, and stored in sealed glass conical flasks. The one hundred mice were intragastrically injected with their chosen $\mathrm{KCN}$ solution using a pipette inserted into the oesophagus. One mouse was injected once for each concentration condition. To adhere to the LD50 of KCN mg/g-1 for mice, ${ }^{24,25}$ the mass of $\mathrm{KCN}$ injected was different for each mouse as each mouse weighed differently. The volumes used ranged between $229 \mu 1$ and $413 \mu 1$. Samples M-001 to M-020 inclusive was injected with $0 \mathrm{ppm} \mathrm{KCN}$ as a control. The control solution was made up of just deionised water. Samples M-020 to M-40 inclusive were injected with 5000 ppm KCN, M-041 to M-060 inclusive with 10000ppm KCN, samples M-061 to M-080 inclusive were injected with 20000ppm $\mathrm{KCN}$ and finally samples M-081 to M-100 inclusive were injected with 30000ppm KCN.

Once the mouse samples were injected with their KCN concentration condition, they were buried in their labelled container. Every sample was covered with at leasta $10 \mathrm{~mm}$ layer of soil from the container sufficiently so that they could not be seen from an above viewpoint. All samples were stacked together in a Conviron Adaptis CMP6010 incubator with sufficient room for air circulation and incubated at $20^{\circ} \mathrm{C}$. Samples M-001 to M-100 was randomised into four Day Removal Categories (DRCs). The DRCs were 7, 14, 21 and 30 days after initial burial. In each DRC, twenty-five samples were removed once the experiment reached that particular day after the injection date: e.g., Day 14 samples were removed fourteen days after injection day. On each DRC, twenty-five samples were removed from their containers and cleaned of residual soil with brushes very carefully. Once the sample had been sufficiently cleaned, it was placed in a pre-weighed petri dish and weighed to three decimal places. This weight was recorded and labelled as its Removal Weight after the subtraction of the petri dish weight. Once weighed, the mouse sample was photographed and the soil and biological samples were disposed of. The difference between Initial and Removal weights of all one hundred samples were calculated and recorded as both a percentage change and gram change.

\section{Statistical methodology}

Graphs and statistical analysis were produced using IBM SPSS Statistics Predictive Analytics Software Version 22 (SPSS). Statistic methods used were Levene's Test of Homogeneity of Variances with a significant figure of 0.05 . Results $\geq 0.05$ in Levene's Test were considered a pass, to which were analysed with oneway ANOVA with a $\mathrm{P} \leq 0.05$ being significant. Results $\leq 0.05$ in Levene's Test were analysed with Welch's F-Test with a $\mathrm{P} \leq 0.05$ also being significant.

\section{Qualitative methodology}

Qualitative analysis of scoring decomposition was performed using Megyesi et al., ${ }^{1}$ method. For this method, the mouse sample was scored in three areas: the head, the body, and the limbs with tail. This scoring scheme was divided into four main phases: Fresh, Early Decomposition, Advance Decomposition and Skeletonisation. Each phase was further divided into a number of stages based on the general characteristics of the remains and scored a point value. Each group of mouse samples were described and issued a number of scores as to what was observed. The samples could be given more than one point as long as justification was used. The total numbers of points between the three areas were accumulated to give a Total Body Score (TBS). As Megyesi et al.'s method was originally proposed and used on human cadavers; Table 1 was edited to include tail observations. The rest of Tables $1-3$ remain largely identical to Megyesi et al. ${ }^{1}$ original tables. 
Table I Categories and stages of decomposition for the limbs and tail.'

\begin{tabular}{lll}
\hline Stage & Points & Description \\
\hline Fresh & I & Fresh, no discolouration. \\
Early Decomposition & 2 & Pink, white appearance with skin slippage of limbs and tail \\
& 3 & Grey to green discolouration; marbling; some flesh still relatively fresh \\
& 4 & Discolouration and/or brown shades particularly at edges, drying of projecting extremities \\
& 5 & Brown to black discolouration, skin having a leathery appearance. \\
Advance Decomposition & 6 & Moist decomposition with bone exposure less than one half of the area being scored. \\
& 7 & Mummification with bone exposure less than one half that of the area being scored. \\
Skeletonisation & 8 & Bone exposure over one half of the area being scored, some decomposed tissue and body fluids remaining. \\
& 9 & Bones largely dry, but retaining some grease. \\
& 10 & Dry bone.
\end{tabular}

Table 2 Categories and stages of decomposition for the head.'

\begin{tabular}{|c|c|c|}
\hline Stage & Points & Description \\
\hline Fresh & I & Fresh, no discolouration. \\
\hline \multirow[t]{5}{*}{ Early Decomposition } & 2 & Pink, white appearance with skin slippage and some hair loss. \\
\hline & 3 & Grey to green discolouration some flesh still relatively fresh. \\
\hline & 4 & Discolouration and/or brown shades particularly at edges, drying of nose, ears and lips. \\
\hline & 5 & Purging of decompositional fluid out of eyes, ears, nose, mouth, some bloating of face may be present. \\
\hline & 6 & Brown to black discolouration of flesh \\
\hline Advance Decomposition & 7 & Caving in of flesh and tissues of eyes and throat \\
\hline \multirow[t]{2}{*}{ Advance Decomposition } & 8 & Moist decomposition with bone exposure less than one half of the area being scored. \\
\hline & 9 & Mummification with bone exposure less than one half that of the area being scored. \\
\hline \multirow[t]{4}{*}{ Skeletonisation } & 10 & Bone exposure of more than half of the area being scored with greasy substances and decomposed tissue. \\
\hline & 11 & Bone exposure of more than half the area being scored with desiccated or mummified tissue. \\
\hline & 12 & Bones largely dry, but retaining some grease. \\
\hline & 13 & Dry bone. \\
\hline
\end{tabular}

Table 3 Categories and stages of decomposition for the body.

\begin{tabular}{|c|c|c|}
\hline Stage & Points & Description \\
\hline Fresh & I & Fresh, no discolouration. \\
\hline \multirow[t]{4}{*}{ Early Decomposition } & 2 & Pink, white appearance with skin slippage and marbling present. \\
\hline & 3 & Grey to green discolouration some flesh still relatively fresh. \\
\hline & 4 & Bloating with green discolouration and purging of decompositional fluids. \\
\hline & 5 & Post-bloating following release of the abdominal gases, with discolouration changing from green to black \\
\hline \multirow[t]{3}{*}{ Advance Decomposition } & 6 & Decomposition of tissue producing sagging of flesh; caving in of the abdominal cavity. \\
\hline & 7 & Moist decomposition with bone exposure less than one half of the area being scored. \\
\hline & 8 & Mummification with bone exposure less than one half that of the area being scored. \\
\hline Skeletonisation & 9 & Bone exposure of more than half of the area being scored with greasy substances and decomposed tissue. \\
\hline \multirow[t]{2}{*}{ Skeletonisation } & 10 & Bone exposure of more than half the area being scored with desiccated or mummified tissue. \\
\hline & 12 & Dry bone. \\
\hline
\end{tabular}




\section{Results and discussion}

\section{Statistical analysis of mass loss interpretation}

Statistical analysis of all mean percentage changes for all four DRCs resulted in non-significant results for oneway ANOVA and Welch's F-tests. The non-significance of these results suggests that carbon and nitrogen rich poisons such as potassium cyanide do not disturb normal soil microbial functions leading to an increase in the rate of microbial activity. This is a highly surprising result for two reasons. Firstly, it is well known that 'resource quality' is inversely proportional to the ratio of carbon and nitrogen; i.e. a high ratio indicates a poor-quality resource and vice versa. ${ }^{26}$ For example, cow manure contains a carbon: nitrogen ratio of $18: 1$ whereas plant material is approximately $100: 1 .^{27}$ In this example, cow manure is a higher-quality resource. $\mathrm{KCN}$ has a carbon: nitrogen ratio of 1:1 therefore would be favourable source. If this was the case, cadaver decomposition would have been observed to increase with added KCN compared to the control condition, but this was not true. Secondly, soil contains bacteria and fungi that have evolved to utilise cyanides as sources of carbon and nitrogen, however the increase in carbon and nitrogen from this specific source was not enough to increase these microbes' activity. One likely theory about why this increase did not occur could be a result of nutrient competition. Concentrations of $\mathrm{KCN}$ (5000ppm, 10000ppm and 20000ppm) showed a lower percentage mass change compared to the control. It is speculated that soil-borne and cadaver-borne microbes competed for both the carbon and nitrogen released from the decomposing cadaver and that from $\mathrm{KCN}$. As the concentration of $\mathrm{KCN}$ increased between 5000ppm and $20000 \mathrm{ppm}$, more carbon and nitrogen was available for microbes to use for growth, thus decreasing the rate of decomposition. That said the rate of decomposition was not commensurate with increasing $\mathrm{KCN}$ concentrations in the abdomen statistically.

\section{Qualitative analysis of mass loss}

Megyesi et al., ${ }^{1}$ decomposition scoring system has only been tested on human cadavers when laid on surfaces and not, as in this investigation, using buried Mus musculus animal cadavers. Thus, there is some discrepancy when using a qualitative model on unfamiliar remains. Nonetheless, it has performed well with its unaccustomed cadavers, which should give this model some increased reliability when using it on other species.

Individual differences between all the samples across each DRC were minimal. During DRC 7 it was observed that the majority of mouse samples, regardless of KCN conditions, had reached the 'Early Decomposition' stage, as a slight inflation of abdomen was visible. At DRC 14, many of the samples had completed the 'Early Decomposition' stage and were observed to be in Advance Decomposition' stage with strong odours of decay, compared to other DRCs, and the beginnings of fur loss as well as the sample becoming more wet, probably due to a combination of inner-body water leakage from apoptosis as well as from the soil itself. The soil tended to clump and attach itself onto the skin and when attempted to be removed by hand, occasionally sample skin was removed, indicating skin slippage and decay. During DRC 21, much like DRC 30, the carcasses were beginning to lose their remaining fluids because the soil became easier to remove from the already decayed skin suggesting a "late flaccidity and dehydration stage"1 or 'Advance Decomposition' or 'Skeletonisation' stage.

\section{Qualitative analysis of head}

The only differences that occurred to the head during observational analysis occurred during and after DRC 14. Only 30000ppm KCN condition cadavers had bone exposure, albeit a greasy appearance, on the head region. It is unknown what caused this; however, one theory proposed is that some of the cyanide from the stomach was forced up the oesophagus into the oral cavity during 'Early Decomposition' as purging fluid tends to leak from the eyes, ears, nose and mouth, possibly releasing sources of carbon and nitrogen into the surrounding area for microbes to utilise.

Qualitative analysis of body: While there were no observational differences during DRC 7, 21 and 30, DRC 14 showed that there is possibly a positive correlation between $\mathrm{KCN}$ concentration and localised abdominal decomposition as indicated by an increasing discernible concavity of the abdomen. Figure 1, the control, had a horizontal abdomen shape and, as the KCN concentration increases to Figure 2, the abdomen became substantially more concave. Reasoning for this could be due to the stomach decaying around DRC 14 and releasing the cyanide into the surrounding soil for microbes to use.

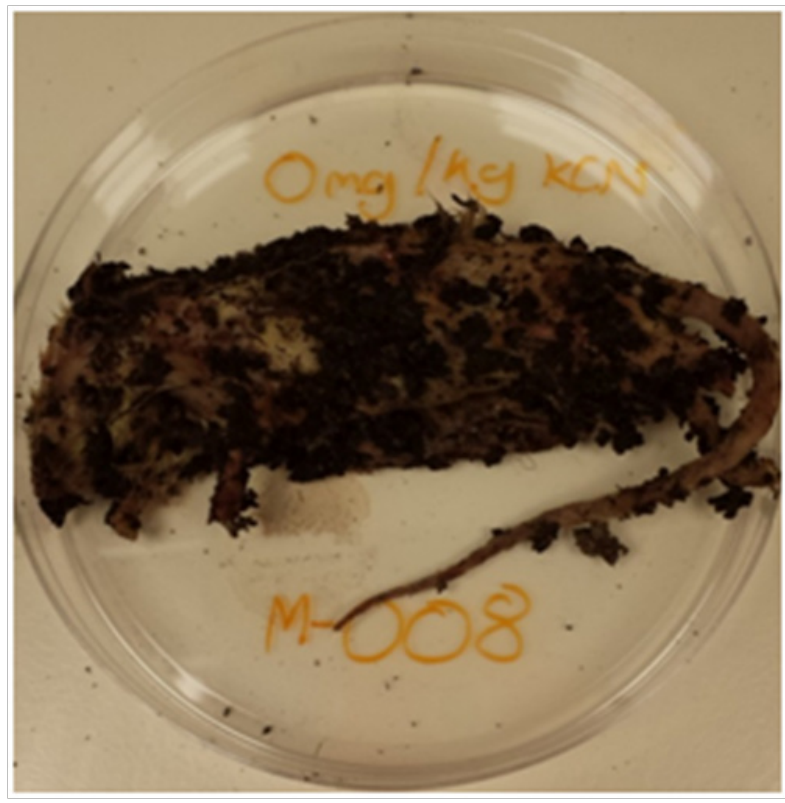

Figure I M-008 control sample 14 days removed.

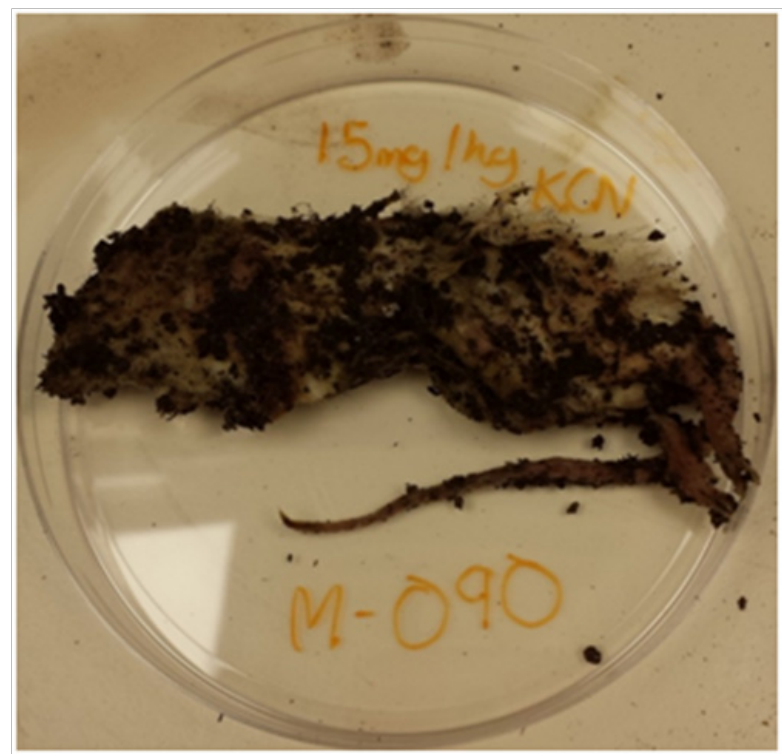

Figure 2 M-090 30mg/ml potassium cyanide sample I 4 days removed. 


\section{Qualitative analysis of limbs and tail}

During DRC 14, mice in 5000ppm KCN concentration condition had noticeably more decomposed tails compared to other $\mathrm{KCN}$ conditions. This is visible in comparisons of Figure 3 and other Figures from DRC 14 (Figure 4 \& Figure 5). There is little likelihood that this difference in tail decomposition is down to a specific concentration of $\mathrm{KCN}$, though it is suprising that $5000 \mathrm{ppm} \mathrm{KCN} \mathrm{mice} \mathrm{were} \mathrm{the}$ only ones with slightly elevated decomposed tails compared to the other samples. These differences may be down to what the position the tails were in relation to the rest of the body. It is noted that M-033 sample's tail was extended further away from the animal's main body compared to the other samples. This difference in tail position may have influenced its own rate of decomposition as bacteria in the soil surrounding the tail may have had slight differences to those further away.

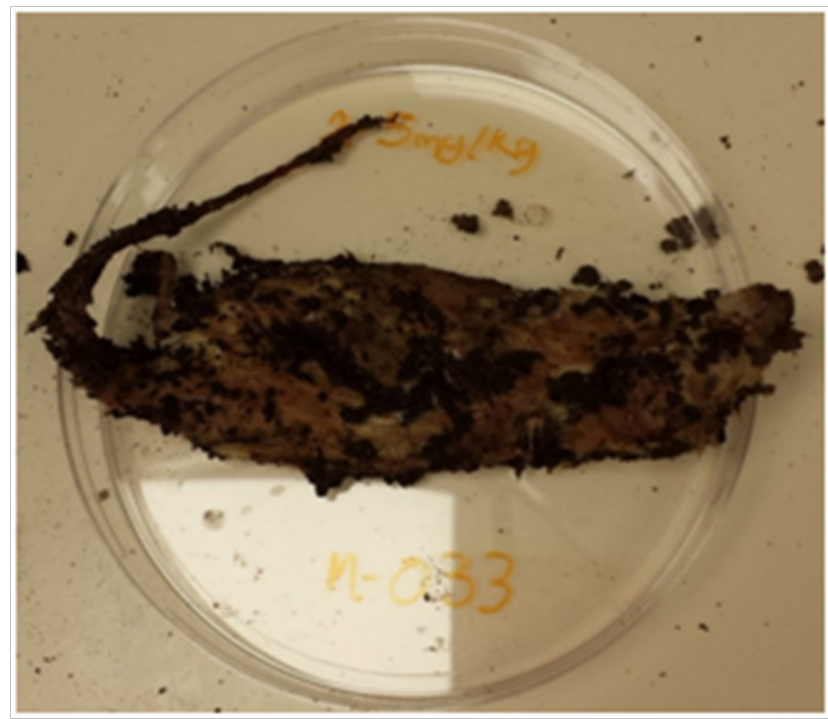

Figure $3 \mathrm{M}-0335 \mathrm{mg} / \mathrm{ml}$ potassium cyanide sample I4days removed.

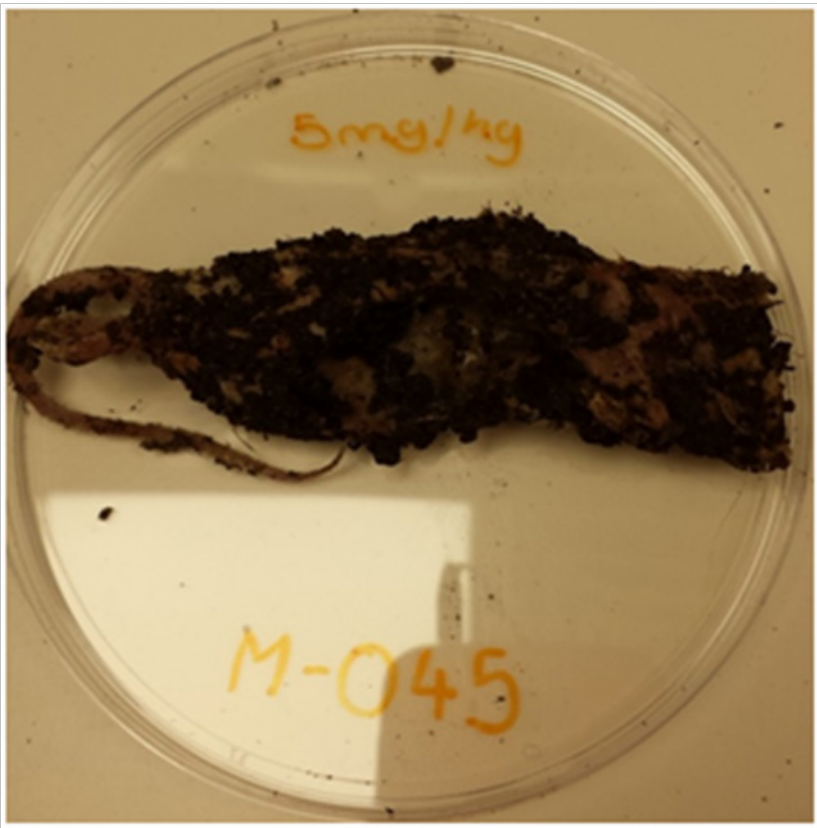

Figure 4 M-045 IOmg/ml potassium cyanide sample I4days removed.

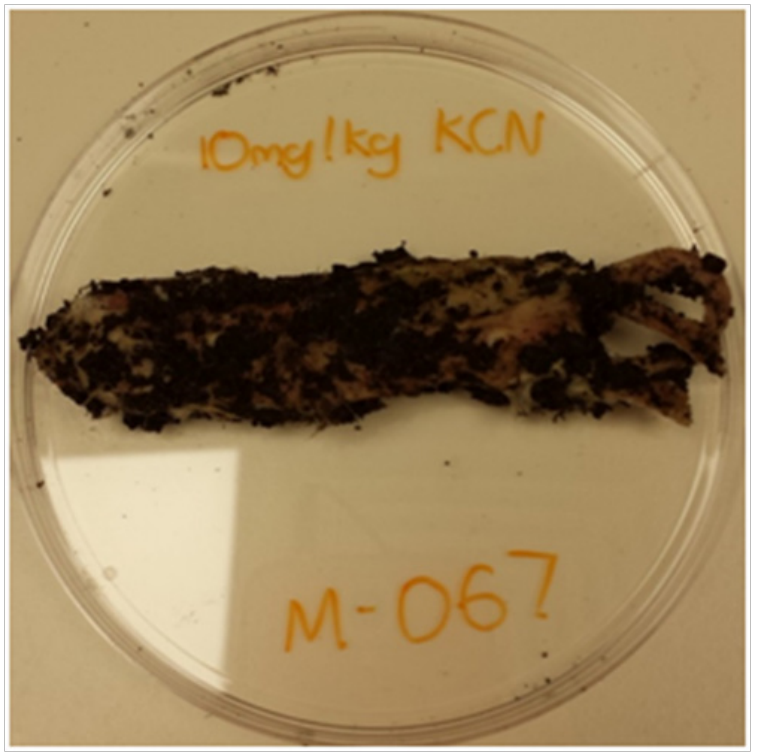

Figure 5 M-067 20mg/ml potassium cyanide sample I4days removed.

\section{Overall results}

Figure 6 is a graph showing the mean mass change in percentage for each set of samples removed at DRC 7, 14, 21 and 30. Figure 6 shows all percentage masses increased from initial weights to DRC 7 between $10 \%-22 \%$. All mean mass changes then declined steadily. 0ppm and 20000ppm results intersect at DRC 14. At DRC $14,10000 \mathrm{ppm}$ plunged to about $22.307 \%$, while $0 \mathrm{ppm}$, 5000ppm and $20000 \mathrm{ppm}$ remain closely together around 10\%. 30000ppm lies in between both groups around $16.054 \%$. Between DRC 14 and 21, pairs $0 \mathrm{ppm}$ and 5000ppm, and 20000ppm and 30000ppm stay almost parallel with each other while steadily decreasing to around $30 \%$ while $20000 \mathrm{ppm}$ and $30000 \mathrm{ppm}$ have a larger gap between them of $4.886 \%$. $10000 \mathrm{ppm}$ remains steady, almost plateauing, for the remainder of the experiment before finishing on DRC 30 at 27.311\%. 10000ppm and30000ppm intersect 0ppm and 5000ppm around day 19. Between DRC 21 and 30, 30000ppm sharply dropped from $26.748 \%$ to $42.823 \%$ to end with the largest mean mass change of all KCN conditions. 20000ppm continued to fall at the same rate as during DRC 14 to 21 and intersected $10000 \mathrm{ppm}$ around day 26 . $0 \mathrm{ppm}$ and 5000ppm continued to remain parallel until the end of the experiment.

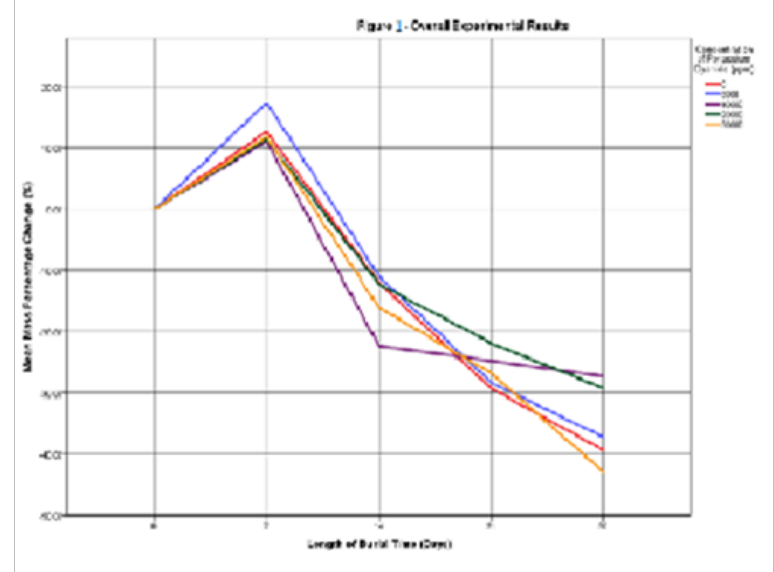

Figure 6 Overall experimental results. 


\section{Qualitative analysis}

A small number of photographs were taken of the mouse samples as they were, the main qualitative analysis was performed contemporaneously, and observations noted. The scores for the decomposition stages of the head are summarised in Table 4, the body in Table 5, the limbs and tail in Table 6 and, finally, a total body score summary in Table 7 from the addition of figures from Tables 4-6.

Table 4 Stages of decomposition scores for the head

\begin{tabular}{llllll}
\hline \multicolumn{5}{c}{ KCN concentrations (parts per million ppm) } \\
DRC & 0 & 5000 & 10000 & 20000 & 30000 \\
\hline 0 & 5 & 5 & 5 & 5 & 5 \\
7 & 10 & 10 & 10 & 10 & 10 \\
14 & 10 & 20 & 20 & 25 & 48 \\
21 & 80 & 80 & 80 & 65 & 55 \\
30 & 65 & 65 & 65 & 65 & 55 \\
\hline
\end{tabular}

Table 5 Stages of decomposition scores for the body

\begin{tabular}{llllll}
\hline & \multicolumn{5}{c}{ KCN concentrations (parts per million ppm) } \\
\cline { 2 - 6 } DRC & 0 & 5000 & 10000 & 20000 & 30000 \\
\hline 0 & 5 & 5 & 5 & 5 & 5 \\
7 & 16 & 15 & 15 & 15 & 15 \\
14 & 16 & 17 & 17 & 20 & 36 \\
21 & 25 & 25 & 25 & 30 & 55 \\
30 & 40 & 40 & 40 & 40 & 40 \\
\hline
\end{tabular}

Table 6 Stages of decomposition scores for the limbs and tail.

\begin{tabular}{llllll}
\hline \multicolumn{5}{c}{ KCN Concentrations (parts per million ppm) } \\
DRC & 0 & $\mathbf{5 0 0 0}$ & 10000 & $\mathbf{2 0 0 0 0}$ & $\mathbf{3 0 0 0 0}$ \\
0 & 5 & 5 & 5 & 5 & 5 \\
7 & 15 & 15 & 15 & 15 & 15 \\
14 & 15 & 50 & 15 & 15 & 15 \\
21 & 30 & 30 & 30 & 30 & 30 \\
30 & 35 & 35 & 35 & 35 & 35 \\
\hline
\end{tabular}

Table 7 Total body scores per KCN concentration for each DRC

\begin{tabular}{llllll}
\hline & \multicolumn{5}{c}{ KCN Concentrations (parts per million ppm) } \\
\cline { 2 - 6 } DRC & 0 & 5000 & 10000 & 20000 & 30000 \\
\hline 0 & 15 & 15 & 15 & 15 & 15 \\
7 & 41 & 40 & 40 & 40 & 40 \\
14 & 41 & 87 & 52 & 60 & 99 \\
21 & 135 & 135 & 135 & 115 & 140 \\
30 & 130 & 130 & 130 & 130 & 130 \\
\hline
\end{tabular}

Qualitative analysis through observations shows that there were minimal differences between $\mathrm{KCN}$ concentrations and the scores for the head at each DRC. All Initial (DRC 0) cadavers were buried when
'Fresh' so were given a score of 1 (totalling 5 for all 5 cadavers). Observations of all $\mathrm{KCN}$ concentrations remained the same for DRC 7 as all mice remained pink with minor skin slippage when touched and a lack of marbling. According to Megyesi et al.'s scoring system, at DRC 7 the mice were in the first stages of 'Early Decomposition' as none of them had advanced past a pink/white skin appearance or had any signs of bloating.

At DRC 14, differentiation began to occur. As the KCN concentrations increased, different observations were made which were noted in the scores. The controls remained as they were with only a minor removal of facial fur. As the KCN concentration increased, discolouration began to appear; from grey almost to black. Purging of fluids was also observed and the eye orbitals began to appear due to the loss of the eyes. In the highest $\mathrm{KCN}$ concentration, bone was exposed in over half of the cadavers suggesting that these individuals had progressed into both 'Advance Decomposition' and 'Skeletonisation' in around 7 days. During excavation on DRC 21, higher KCN concentrations had a lower Total Point score of 55 compared to other lower concentrations score of 80 . This was due to observations of both caving in of fleshy facial areas as well as bone exposure. Therefore they were awarded both 7 and 9 points collectively. Only 20000ppm and 30000ppm cadavers had mummification with bone exposure observed at DRC 14 resulting in an 11 point award totalling 55 for individuals. Lastly, on DRC 30, all samples had reached the 'Skeletonisation' stage of the scoring system and were each awarded 11 points totalling 65 as shown. When initially buried, the cadavers were in the 'Fresh' stage and were given a score of 1 (totalling 5 for all 5 cadavers). Observations of all $\mathrm{KCN}$ concentrations remained the same for DRC 7 as all mice remained pink with minor skin slippage when touched and a lack of marbling, except in one instance where one mouse sample (M-040) had displayed green lines on its underbelly, which was awarded a 4 . Similar to that which was observed on the head, higher concentrations of KCN appeared to have increased body area decomposition during DRC 14 and 21 much to the point that the $30000 \mathrm{ppm}$ was in an 'Advance Decomposition' state. All had areas of dark green or black discolouration and a minimal amount of bloating. The concavity of the abdominal area seemed to increase as the KCN concentration increased. Lastly, on DRC 30 there was no difference in scores (40) as all samples had reached a moist-mummification stage in 'Advance Decomposition' but all displayed a lack of bone exposure. Qualitative analysis of the limbs and tail Table 6 shows that there were no score differences throughout the KCN concentrations across all DRC days except on one occasion. It was observed during DRC 14 that cadavers in the 5000ppm KCN condition had a leathery appearance to their tails as well as bone appearance. TBS remained the same for all $\mathrm{KCN}$ concentrations during DRC 0, 7 and 30 . Differences in head and body decomposition raised the TBS in certain concentration conditions. ${ }^{28,29}$

\section{Critical analysis of mass loss model for decomposition}

The final objective of this investigation was to critically analyse whether overall mass loss experienced by the cadaver was a viable method for assisting in PMI estimations. The difficulty with mass loss is, firstly, the requirement of an initial weight to compare to the weight of the decomposing body. Finding the initial weight becomes difficult if the victim has not recorded their weight ante-mortem. However, whole patient weights are recorded in many hospitals, and in addition there is a common practice of weighing organs taken during autopsies. ${ }^{30}$ These recorded values may have more of a clinical value rather than forensic if the victim dies close to the time these values 
were recorded. Secondly, there are numerous variables affecting the weights of humans, post-mortem. Depending on burial conditions, water and soil attachment can play an influencing role in human weight differences, as well as entomological and scavenger effects, such as maggot weight and the removal of body parts by scavengers, may be needed to be taken into account and pathological effects, such as carcinomas increasing body weight. As mentioned before, there are environmental factors that will affect the rate of decomposition such as temperature and humidity that must be either known or estimated, with the risk of affecting accuracy, to estimate PMI. With the extensive network of body mass influences that alter their effects during decomposition, as well as huge ranges in individual's weights ante-mortem it seems that overall mass loss is neither a reliable nor an accurate method of estimating PMI in forensic settings. In an ideal case whereby initial weight of the individual, burial conditions, environmental, entomological and pathological effects are known and taken into account, then overall mass loss could be used to attempt to estimate PMI.

\section{Conclusion}

This study was conducted to determine whether carbon and nitrogen rich poisons had an effect on soil microbial growth that in turn would affect the rate of decomposition of Mus musculus. It was also conducted to determine whether these poisons had a qualitative effect on the body. It was demonstrated that potassium cyanide had no statistically significant effect on the overall rate of decomposition of the mouse samples. However, photographic evidence of the samples suggested that not only do carbon and nitrogen rich poisons have a localised effect on the abdomen, but they also display a proportional effect through the observed increase in decomposition of the abdomen, the area which has the highest concentration of orally consumed cyanide solution. This study also set out to critically analyse whether general mass loss is a viable model for assisting in PMI estimations of a cadaver. Results from this investigation deemed general mass loss too difficult to use to accurately estimate PMI due to the numerous environmental, biological, pathological and individual variables that would have to have been taken into account, many of which are lost at the point of death. With an increased number of fatal poisoning cases throughout the United Kingdom, it is important to assess the consequences poisons have on post-mortem bodies. This research has taken a step forward in this surprisingly empty area of forensic science and has added valuable information to the already scarce repository of evidence of what effect poisons have on cadaver decomposition. Recommended future consideration regarding poisons and decomposition include: changes to sampling parameters, such as shorter exhumation periods, consideration of the effects pharmaceutical drugs and the elements have on microbial growth and extending post-burial intervals leading to skeletonisation.

\section{Acknowledgments}

The author would like to acknowledge Dr. Iain Green and Bournemouth University, Dorset, United Kingdom for the financial support.

\section{Conflicts of interest}

The author declared no potential conflicts of interest with respect to the authorship and/or publication of this article.

\section{References}

1. Megyesi MS, Nawrocki SP, Haskell NH. Using Accumulated DegreeDays to Estimate the Postmortem Interval from Decomposed Human Remains. J Forensic Sci. 2005;50(3):1-9.
2. Payne JA. A summer carrion study of the baby pig Sus scrofa Linnaeus. Ecology. 1965;46(5):592-602.

3. Ying L, Chen YQ, Guo YD, et al. Estimation of post-mortem interval for a drowning case by using flies (Diptera) in Central-South China: Implications for forensic entomology. Romanian Journal of Legal Medicine. 2013;21(4):293-298.

4. Rodriguez WC, Bass WM. Insect activity and its relationship to decay rates of human cadavers in east Tennessee. Journal of Forensic Sciences. 1983;28(2):423-432.

5. Rodriguez WC, Bass WM. Decomposition of buried bodies and methods that may aid in their location. J Forensic Sci. 1985;30(3):836-852.

6. Payne JA, King EW, Beinhart G. Arthropod succession and decomposition of buried pigs. Nature. 1968;219(5159):1180-1181.

7. Micozzi MS. Experimental study of post-mortem change under field conditions: effects of freezing, thawing and mechanical injury. J Forensic Sci. 1986;31(3):953-961.

8. Turner BD, Wiltshire P. Experimental validation of forensic evidence: study of the decomposition of buried pigs in a heavy clay soil. Forensic Sci Int. 1999;101(2):113-122.

9. Carter DO, Yellowlees D, Tibbett M. Temperature affects microbial decomposition of cadavers (Rattusrattus) in contrasting soils. Applied Soil Ecology. 2008;40(1):129-137.

10. Carter DO, Tibbett M. Microbial decomposition of skeletal muscle tissue (Ovisaries) in a sandy loam soil at different temperatures. Soil Biology and Biochemistry. 2006;38(5):1139-1145.

11. Fitzpatrick RW. Nature, Distribution, and Origin of Soil Materials in the Forensic Comparison of Soils. Soil Analysis in Forensic Taphonomy: Chemical and Biological Effects of Buried Human remains. CRC Press, USA. 2008;1-28.

12. Carter DO, Tibbett M. Moisture can be the dominant environmental parameter governing cadaver decomposition in soil. Forensic Sci Int. 2010;200(1-3):60-66.

13. Morovic-Budak A. Experiences in the process of putrefaction in corpses buried in earth. Med Sci Law. 1965;5:40-43.

14. Forbes SL, Dent BB, Stuart BH. The effect of soil type on adipocere formation. Forensic Sci Int. 2005;154(1):35-43.

15. Tibbett M. Blood, gits, gore and soil: decomposition processes in graves and forensic taphonomic applications. 2010;1-4.

16. Towill LE, Drury JS, Whitfield BL, et al. Reviews of the environmental effects of pollutants: V. Cyanide. Environmental Protection Agency, USA. 1978;210.

17. Schnepp R. Cyanide: sources, perceptions and risks. J Emerg Nurs. 2006;32(4):S3-S7.

18. Borron SW, Baud FJ, Mégarbane B, et al. Hydroxocobalamin for severe acute cyanide poisoning by ingestion or inhalation. Am J Emerg Med. 2007;25(5):551-558.

19. Shepherd G, Velez L. Role of hydroxocobalamin in acutecyanide poisoning. Ann Pharmacother. 2008;42(5):661-669.

20. Naveen D, Majumder CB, Mondal P, et al. Biological Treatment of Cyanide Containing Wastewater. Research Journal of Chemical Sciences. 2011;1(7):15-21.

21. Saidu Y. Physiochemical features of Rhodanese: A Review. African Journal of Biotechnology. 2004;3(4):370-374.

22. Cipollone R, Ascenzi P, Fragipani E, et al. Cyanide detoxification by recombinant bacterial Rhodanese. Chemosphere. 2006;63(6):942-949.

23. Gallagher LA, Manoil C. Pseudomonas aeruginosa PAO1 Kills Caenorhabvditis elegans by Cyanide Poisoning. $J$ Bacteriol. 2001;183(21):6207-6214. 
24. Scientific Committee on Occupational Exposure Limits (SCOEL). Recommendation from the Scientific Committee on Occupational Exposure Limits for Cyanide ( $\mathrm{HCN}, \mathrm{KCN}, \mathrm{NaCN})$. European Commission of Employment. 2010;1-14.

25. Environmental Protection Agency (EPA). Toxicological Review of Hydrogen Cyanide and Cyanide Salts. Integrated Risk Information System, Washington, USA. 2010.

26. Damann FE, Carter DO. Human Decomposition Ecology and Postmortem Microbiology. In: Symes SA, et al (editors). Manual of Forensic Taphonomy. Taylor \& Francis Group LLC, CRC Press, USA. 2013;37-50.
27. Carter DO, Yellowlees D, Tibbett M. Cadaver Decomposition in Terrestrial Ecosystems. Naturwissenschaften. 2007;94(1):12-24.

28. Clark MA, Worrell MB, Pless JE. Postmortem changes in soft tissue. In: Haglund WD et al, (editors). Forensic Taphonomy: The Postmortem Fate of Human Remains. CRC Press, USA. 1996;151-164.

29. Gill-King H. Chemical and ultrastructural aspects of decomposition. In: Haglund WD et al, (editors). Forensic Taphonomy: The Postmortem Fate of Human Remains. CRC Press, USA. 1997;93-108.

30. De la Grandmaison GL, Clairand I, Durigon M. Organ weight in 684 adult autopsies: new tables for a Caucasoid population. Forensic Sci Int. 2001;119(2):149-154. 